\title{
A new antispastic solution for arterial grafting: Nicardipine and nitroglycerin cocktail in preparation of internal thoracic and radial arteries for coronary surgery
}

\author{
Guo-Wei He, MD, PhD, DSc, ${ }^{a, b, c}$ Li Fan, MD, PhD, ${ }^{a}$ Anthony Furnary, MD, ${ }^{c}$ and Qin Yang, MD, PhD ${ }^{b}$
}

Supplemental material is available online.
From the Nankai University Medical College and TEDA International Cardiovascular Hospital, ${ }^{\text {a }}$ Tianjin, China; Department of Surgery, The Chinese University of Hong Kong, ${ }^{\mathrm{b}}$ Hong Kong, China; and Providence Heart and Vascular Institute, Albert Starr Academic Center, Department of Surgery, Oregon Health and Science University, ${ }^{\mathrm{c}}$ Portland, Oregon.

This work was fully supported by Research Grants Council of the Hong Kong Special Administrative Region (Project No. CUHK4383/03M, CUHK4651/07M) and CUHK Direct Grant 2041164, 4450171, 4450169, 2041305, 4450231, China, and grants from Providence St Vincent Medical Foundation, Portland, Oregon.

Received for publication Oct 4, 2007; revisions received Nov 5, 2007; accepted for publication Dec 24, 2007.

Address for reprints: Professor Guo-Wei He, MD, PhD, DSc, Department of Surgery, The Chinese University of Hong Kong, Block B, 5A, Prince of Wales Hospital, Shatin, N.T., Hong Kong SAR, China (E-mail: gwhe@ cuhk.edu.hk).

J Thorac Cardiovasc Surg 2008;136:673-80 $0022-5223 / \$ 34.00$

Copyright $(2008$ by The American Association for Thoracic Surgery

doi:10.1016/j.jtcvs.2007.12.019
Objective: Antispastic protocols for arterial grafts are important in arterial grafting for coronary artery bypass grafting surgery. We designed a new nicardipine and nitroglycerin cocktail that is composed of a second-generation dihydropyridine calcium antagonist, nicardipine and nitroglycerin $(30 \mu \mathrm{mol} / \mathrm{L})$, and examined its effect in human internal thoracic and radial arteries.

Methods: Human internal thoracic $(\mathrm{n}=86)$ and radial $(\mathrm{n}=74)$ artery segments from 72 patients undergoing coronary artery bypass grafting were studied. Relaxation against 3 classic vasoconstrictors (potassium chloride, thromboxane $\mathrm{A}_{2}$ mimetic $\mathrm{U} 46619$, and $\alpha$-adrenoceptor agonist norepinephrine) and prophylactic effect on contraction against these vasoconstrictors were examined. The effect of the nicardipine and nitroglycerin cocktail on the endothelial function in internal thoracic and radial arteries was studied in response to acetylcholine.

Results: Nicardipine and nitroglycerin induced almost full relaxation $(92.2 \% \pm 4.7 \%$ to $97.9 \% \pm 1.0 \%, P<.001$ in internal thoracic arteries and $95.4 \% \pm 1.9 \%$ to $96.7 \%$ $\pm 3.3 \%, P<.001$ in radial arteries, $\mathrm{n}=6-8$ ) against 3 vasoconstrictors with significant prophylactic effect on contraction (maximal contraction was depressed to $32.5 \%$ to $76.4 \%, P<.05$ or $P<.001$, and EC50s were increased to 5 to 42 -fold more, $P<.01)$. After treatment with the nicardipine and nitroglycerin cocktail, the acetylcholine-induced relaxation was unchanged $(P>.05)$.

Conclusion: The use of the nicardipine and nitroglycerin cocktail provides a new antispastic protocol that has rapid onset, full relaxation, and excellent prophylactic effect against all known mechanisms of vasospasm and maximally protects the endothelial and smooth muscle function of the internal thoracic and radial arteries. The cocktail is therefore expected to provide a new method in treating grafts in coronary artery bypass grafting with the best antispastic effect and protection of the graft.

$\mathrm{T}$ The antispastic protocol for arterial grafts is important in arterial grafting for coronary artery bypass grafting $(\mathrm{CABG})$ to maximally reduce vasospasm-related complications. ${ }^{1-4}$ The prevention or relief of vasospasm in arterial grafts not only solves the vasospastic problem that reduces the perioperative graft spasm and complications related to it but also plays a role in the long-term patency because of the protective effect of the solution on the endothelium that is related to less surgical manipulation when the artery is relaxed. ${ }^{3,5}$

The antispastic protocol has been evolving since the 1980s. A number of protocols have been recommended. ${ }^{6-27}$ In general, choosing a particular protocol depends on the availability of drugs and the preference of the surgeon. An ideal protocol should take into account the following. First, the drugs have to be effective in both relieving and preventing vasospasm. The former refers to the relaxing effect when the vessel is contracted, and the latter refers to preventing contraction by using the drug(s) beforehand. Second, such a protocol should be able to protect the vascular endothelium as much as 


$$
\begin{aligned}
& \text { Abbreviations and Acronyms } \\
& \begin{aligned}
\text { Ach } & =\text { acetylcholine } \\
\text { CABG } & =\text { coronary artery bypass grafting } \\
\text { ITA } & =\text { internal thoracic artery } \\
\mathrm{K}^{+} & =\text {potassium chloride } \\
\mathrm{NE} & =\text { norepinephrine } \\
\mathrm{NG} & =\text { nicardipine and nitroglycerin } \\
\mathrm{NO} & =\text { nitric oxide } \\
\mathrm{NTG} & =\text { nitroglycerin } \\
\mathrm{RA} & =\text { radial artery } \\
\mathrm{SE} & =\text { standard error } \\
\mathrm{VG} & =\text { verapamil and nitroglycerin }
\end{aligned}
\end{aligned}
$$

possible because intact endothelium is a key structure in the prevention of platelet aggregation, thrombosis, intima proliferation, atherosclerosis, and the eventual occlusion of the vessel. Third, the relaxing effect, blockage of the relevant contractile receptors, and membrane potential changes should be temporary, lasting only during the perioperative period. The benefit of an arterial graft is that it is a living vessel, a "living conduit," with most receptor properties preserved, not a "dead fibrotic conduit." This means that the vessel should be able to contract and relax under various conditions. The contraction and relaxation actions are essential for every small to medium-sized artery in maintaining normal function. The rhythmic motion keeps the artery a living conduit that may be protected from intimal proliferation and atherosclerosis, and therefore will have a superior long-term patency. The best preservation of a vessel is to maintain it at physiologic condition with normal receptor properties. Finally, the ideal protocol should be ecumenically acceptable; this is particularly important in current health systems in many countries, particularly in developing countries.

We previously invented a VG (verapamil and nitroglycerin) solution composed of a calcium antagonist, verapamil, and a nitric oxide (NO) donor, glyceryl trinitrate (nitroglycerin [NTG]), for use in both arterial and venous grafting. Because verapamil is not available in all places and its bradycardia effect may prevent the simultaneous use of a beta-blocker, and because new generations of calcium antagonists have been developed, we designed the present study to investigate a new cocktail that is composed of a second-generation dihydropyridine calcium antagonist: nicardipine and NTG (NG). We tested this cocktail with regard to the above aspects and report the excellent effect of this solution on both human internal thoracic arteries (ITAs) and radial arteries (RAs).

\section{Materials and Methods}

\section{General}

Human ITA $(n=86)$ and RA $(n=74)$ segments were collected from 72 patients (58 men and 14 women with a mean age of 64.2 \pm 0.8 years) undergoing $\mathrm{CABG}$ using these grafts. Approval to use discarded RA tissue was given by the institutional review board at St Vincent Hospital, Portland, Oregon. The surgeon or assistant received consent from each patient before the operation. The details of the method to collect and dissect the human arteries were previously described. ${ }^{1,11}$ The arteries were cut into 3-mm-long rings and suspended on wires in organ baths. ${ }^{1,11}$

\section{Organ-Bath Technique}

A specially designed organ-bath technique was used for this study. The details of the technique have been published. ${ }^{3,28}$ Briefly, each arterial ring was stretched up in progressive steps to determine the individual length-tension curve. A computer iterative fitting program (VESTAND 2.1, Yang-Hui He, Princeton University, $\mathrm{NJ}$ ) was used to determine the exponential line, pressure, and internal diameter. When the transmural pressure on the rings reached $100 \mathrm{~mm} \mathrm{Hg}$, determined from their own length-tension curves, the stretch-up procedure was stopped and the rings were released to $90 \%$ of their internal circumference at $100 \mathrm{~mm} \mathrm{Hg}$. This degree of passive tension was then maintained throughout the experiment.

Because of the importance of endothelium on vascular tone, we intentionally preserved the endothelium by cautiously dissecting and mounting the rings. ${ }^{29,30}$

\section{Protocol}

\section{Effects of Nicardipine and Nitroglycerin Solution}

The effect of the NG solution was tested in 2 ways as follows.

Relaxation effect against 3 classic vasoconstrictors. These experiments were designed to investigate the effect of NG solution in relieving vasospasm developed with relation to depolarization of the cellular membrane potential (potassium chloride $\left[\mathrm{K}^{+}\right]$), thromboxane $\mathrm{A}_{2}$ (U46619), and $\alpha$-adrenoceptors (norepinephrine $[\mathrm{NE}]$ ).

After the normalization procedure, the vascular rings were equilibrated for at least 1 hour. One of the 3 vasoconstrictors $\left(\mathrm{K}^{+} 75 \mathrm{mmol} / \mathrm{L}, \mathrm{U}_{46619} 10 \mathrm{nM}\right.$, or NE $\left.10 \mu \mathrm{mol} / \mathrm{L}\right)$ was added to the organ bath. After the contraction reached a stable level, $30 \mu \mathrm{mol} / \mathrm{L}$ nicardipine and $30 \mu \mathrm{mol} / \mathrm{L} \mathrm{NTG}$ were added. The relaxation time course was recorded. The force during relaxation was measured at 1-minute intervals and expressed as a percentage of the force during precontraction.

Prophylactic effect on contraction against three classic vasoconstrictors. To investigate the prophylactic effect of NG solution on contraction induced by 3 classic vasoconstrictors, 2 ITA or RA segments were taken from the same artery and allocated into 2 groups. One was used as control, and the other was used for pretreatment with NG solution. After equilibration for at least 60 minutes, the ITA $(n=8)$ or RA $(\mathrm{n}=7)$ rings were treated with $30 \mu \mathrm{M} \mathrm{NG}$ for 30 minutes. Cumulative concentration-contraction curves were then established for $\mathrm{K}^{+}(5-100 \mathrm{mmol} / \mathrm{L}), \mathrm{U}_{46619}(-10 \log \mathrm{M}$ to $-6.5 \log \mathrm{M})$, and $\mathrm{NE}(-8.5$ to $-5 \log \mathrm{M})$.

\section{Effect of Nicardipine and Nitroglycerin Solution on the Endothelial Function in Internal Thoracic and Radial Arteries}

A clinically usable solution must have no harmful effect on the endothelium. We therefore tested the effect of $\mathrm{NG}$ 
solution on the endothelial function in ITAs and RAs. ITA or RA rings taken from the same patient were allocated into 2 groups. One was treated with NG solution for 30 minutes, and the other was used as control. The rings were normalized as mentioned above and then equilibrated for 60 minutes. Precontraction of the rings was induced by U46619. Cumulative concentration-relaxation curves to acetylcholine (ACh) $(-10$ to $-6.5 \log \mathrm{M})$ were established. At the maximal relaxation to $\mathrm{ACh}, 30 \mu \mathrm{M}$ NTG was added if $\mathrm{ACh}$ did not induce full relaxation to demonstrate the integrity of the relaxing property.

\section{Design of the Nicardipine and Nitroglycerin Cocktail}

In the above protocol, we tested the effect of NG at a concentration of $30 \mu \mathrm{mol} / \mathrm{L}(-4.5 \log \mathrm{M})$ on the human ITA and RA segments in the organ chamber. From previous studies, ${ }^{8,11,17,31}$ this concentration was expected to have maximal or nearly maximal effect.

\section{Nicardipine and Nitroglycerin Cocktail}

The components of the clinical (NG) cocktail are as follows:

Nicardipine hydrochloride $5 \mathrm{mg}$

NTG $5 \mathrm{mg}$

$8.4 \% \mathrm{NaHCO} 3 \quad 0.3 \mathrm{~mL}^{*}$

Normosol-R solution $\quad 300 \mathrm{ml}$

This cocktail gives a concentration of approximately $30 \mu \mathrm{mol} / \mathrm{L}(-4.5 \log \mathrm{M})$ of nicardipine or $60 \mu \mathrm{mol} / \mathrm{L}$ $(-4.3 \log \mathrm{M}) \mathrm{NTG}$ in an isotonic solution of $\mathrm{pH} 7.1$.

*The $\mathrm{pH}$ of NG (nicardipine hydrochloride $5 \mathrm{mg}$ and NTG $5 \mathrm{mg}$ ) in Normosol-R solution $(300 \mathrm{~mL})$ without adding $\mathrm{NaHCO}_{3}$ is 6.6 . When the amount of $8.4 \% \mathrm{NaHCO}_{3}$ added is more than $0.3 \mathrm{~mL}$, the solution becomes gradually turbid until $\mathrm{pH}=7.4$ with $8.4 \% \mathrm{NaHCO}_{3} 0.5 \mathrm{~mL}$ added. This, however, does not affect the antispastic effect as seen in the results of the present study because the effect of NG solution at the concentration of $30 \mu \mathrm{mol} / \mathrm{L}(-4.5 \log \mathrm{M})$ was tested in the organ bath with a $\mathrm{pH}$ of 7.4 and slightly turbid-looking.

\section{Onset of Nicardipine and Nitroglycerin Solution}

A clinically useful solution for treating arterial grafts should have a rapid onset to relieve vasospasm as quickly as possible. To test the onset of the NG solution, we recorded the relaxation in 1-minute time intervals against all 3 vasoconstrictors.

\section{Data Analysis}

The relaxation of ITA and RA was expressed as a percentage of the vasoconstrictor-induced precontraction. The effective concentration of the constrictor (or dilator) agent that caused $50 \%$ of maximal contraction (or relaxation) was defined as $\mathrm{EC}_{50}$. The detailed methods have been published. ${ }^{1,28}$

All values were expressed as mean \pm standard error. Statistical comparisons of cumulative contraction force and cumulative percentage of relaxation were performed by 2-way analysis of variance followed by Bonferroni's test.
Unpaired $t$ test or analysis of variance was used to test the statistical significance among different constrictors and dilators regarding $\mathrm{EC}_{50}$.

\section{Materials}

$\mathrm{U}_{46619}$ was a product of the Cayman Chemical Company (Ann Arbor, Mich). $\mathrm{K}^{+}$, nicardipine hydrochloride, and L-(-)-norepinephrine(+)-bitartrate salt monohydrate were purchased from Sigma-Aldrich Chemical Co (St Louis, Mo). NTG $(50 \mathrm{mg} / 10 \mathrm{~mL})$ was a product of Laboratories Inc. New York ACh was purchased from Sigma-Aldrich Chemical Co. Stock solutions of different concentrations of $\mathrm{U}_{46619}$ and ACh were kept frozen until required. Other reagents were regular chemical reagents from Sigma Chemical Co and stored at room temperature.

\section{Results}

\section{Resting Parameters of Internal Thoracic and Radial} Arteries

The internal diameter of the vessels at an equivalent transmural pressure of $100 \mathrm{~mm} \mathrm{Hg}\left(\mathrm{D}_{100}\right)$, determined from the normalization procedure, was $2.6 \pm 0.8 \mathrm{~mm}$ in ITA and $2.9 \pm 0.6 \mathrm{~mm}$ in RA segments. The transmural pressure $90 \%$ of $\mathrm{D}_{100}$ was $76.3 \pm 0.6 \mathrm{~mm} \mathrm{Hg}$ in ITA and $76.0 \pm$ $0.5 \mathrm{~mm} \mathrm{Hg}$ in RA $(P=.8)$ segments. The resting force was $3.0 \pm 0.1 \mathrm{~g}$ in ITA and $1.9 \pm 0.1 \mathrm{~g}$ in RA $(P<.001)$ segments.

\section{Contraction Force in Internal Thoracic and Radial Arteries}

In ITAs, the precontraction force was $1.1 \pm 0.03 \mathrm{~g}$ to $\mathrm{K}^{+}$, $5.7 \pm 0.4 \mathrm{~g}$ to $\mathrm{U}_{46619}\left(P<.001 \mathrm{vs} \mathrm{K}^{+}\right)$, and $2.0 \pm 0.3$ to NE $\left(P>.05\right.$ vs $\mathrm{K}^{+}, P<.001$, vs $\left.\mathrm{U}_{46619}\right)$. In RAs, the precontraction force was $1.2 \pm 0.07 \mathrm{~g}$ to $\mathrm{K}^{+}, 7.5 \pm 0.9 \mathrm{~g}$ to $\mathrm{U}_{46619}\left(P<.001, \mathrm{vs} \mathrm{K}^{+}\right)$, and $1.8 \pm 0.2$ to $\mathrm{NE}(P>.05$ vs $\mathrm{K}^{+}$and $P<.001$ vs $\left.\mathrm{U}_{46619}\right)$.

\section{Effects of Nicardipine and Nitroglycerin Solution}

Relaxation effect against 3 classic vasoconstrictors. NG at a concentration of $30 \mu \mathrm{mol} / \mathrm{L}$ caused almost full $(>90 \%)$ relaxation in ITA rings precontracted with $10 \mathrm{nM} \mathrm{U_{46619 }}$ $(92.2 \% \pm 4.7 \%, \mathrm{n}=8), 70 \mathrm{mmol} / \mathrm{L} \mathrm{K}^{+}(93.9 \% \pm 2.6 \%$, $\mathrm{n}=8)$, and $10 \mu \mathrm{M} \mathrm{NE}(97.9 \% \pm 1.0 \%, \mathrm{n}=8)(P>.05)$ (Figure 1, A).

$\mathrm{NG}$ at a concentration of $30 \mu \mathrm{mol} / \mathrm{L}$ induced almost full relaxation in RA rings $\left(95.4 \% \pm 1.9 \%\right.$ of $\mathrm{U}_{46619}$ precontraction, $96.7 \% \pm 3.3 \%$ of $\mathrm{K}^{+}$precontraction, and $95.8 \% \pm 1.6 \%$ of NE precontraction; $\mathrm{n}=6$ in each group) (Figure 1, B).

\section{Onset of Nicardipine and Nitroglycerin Solution}

The NG solution has a rapid onset of relaxation against all 3 vasoconstrictors, as shown in Figure 2. At 5 minutes, the relaxation reached $60.8 \% \pm 6.5 \%$ against $U 46619,55.6 \%$ $\pm 6.1 \%$ against $\mathrm{K}$, and $92.6 \% \pm 3.0 \%$ against $\mathrm{NE}$ in the 


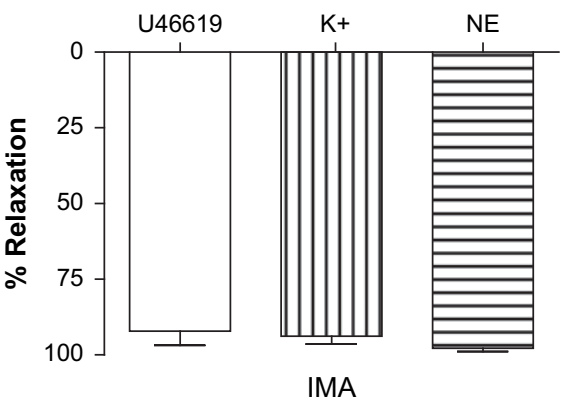

A

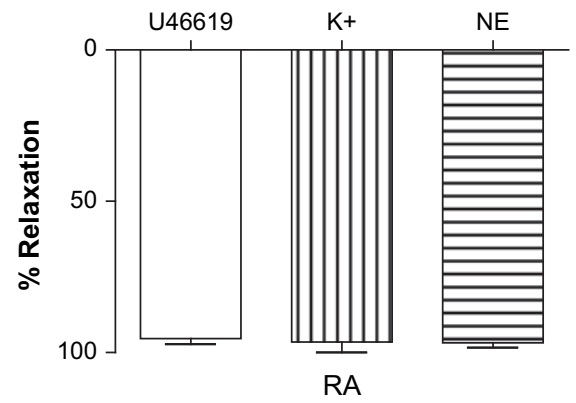

B
Figure 1. Percentage of relaxation induced by nicardipine (30 $\mu \mathrm{mol} / \mathrm{L})$ and glycerol trinitrate (nitroglycerin, NTG $30 \mu \mathrm{mol} / \mathrm{L})$ in ITA (, $\mathrm{n}=8$ ) and RA (B, $n=6)$ rings precontracted by $U_{46619}(10$ $\mathrm{nM}), \mathrm{K}^{+}(70 \mathrm{mmol} / \mathrm{L})$, or NE $(10 \mu \mathrm{M})$. Values are expressed as mean \pm standard error (SE). $P>.05$ (one-way analysis of variance followed by Bonferroni's multiple comparison test). ITA, Internal thoracic artery; $R A$, radial artery; $N E$, norepinephrine; $K^{+}$, potassium chloride.
ITA rings. Similarly, the relaxation reached $64.4 \% \pm 7.3 \%$ against $\mathrm{U} 46619,63.4 \% \pm 6.3 \%$ against $\mathrm{K}$, and $75.1 \% \pm$ $14.6 \%$ against $\mathrm{NE}$ in the RA rings. At 20 minutes, the relaxation reached submaximal $(77 \%-96 \%$ in ITA rings and $76 \%-86 \%$ in RA rings) and lasted to the end of experiment $(>120$ minutes, Figure 2).

Prophylactic Effect on Contraction Against Three Classic Vasoconstrictors (Depression of Contraction by Pretreatment with Nicardipine and Nitroglycerin) Pretreatment with $30 \mu \mathrm{mol} / \mathrm{L} \mathrm{NG}$ for 30 minutes significantly depressed the magnitude of the contraction induced by $\mathrm{U}_{46619}$ (Figure 3), $\mathrm{K}^{+}$(Figure 4), and NE (Figure 5) in both human ITA (Figures 3-5, A) and RA rings (Figures 3-5, B).

Pretreatment of ITA and RA with NG also significantly desensitized the vessel to the 3 classic vasoconstrictors. The $\mathrm{EC}_{50}$ values for $\mathrm{U}_{46619}$-contracted ITA and RA rings incubated with NG were 7 -fold $(P<.001)$ and 5 -fold $(P<.01)$ higher than that of control. In addition, $\mathrm{EC}_{50}$ values of $\mathrm{K}^{+}$ were 6 -fold $(P<.01)$ higher than that of control in RA rings and 42 -fold $(P<.001)$ higher than that of NE in ITA rings. In addition, the maximal contraction force in treated groups was $76.4 \%(P<.05), 52.5 \%(P<.001)$, and $32.5 \%(P=.001)$ of the corresponding control in $\mathrm{U}_{46619}, \mathrm{~K}^{+}$, and NE-contracted ITA rings and $69.2 \%(P<.01), 40.3 \%(P<.05)$, and $15.6 \%$ $(P<.001)$ in RA rings.

\section{Effect of Nicardipine and Nitroglycerin Solution on the Endothelial Function in Internal Thoracic and Radial Arteries}

Cumulative concentration-relaxation curves for ACh were established in $\mathrm{U}_{46619}$-contracted ITA and RA rings incubated with or without $30 \mu \mathrm{mol} / \mathrm{L} \mathrm{NG}$ (Figure E1.). There were no significant differences with regard to the maximal relaxation or the $\mathrm{EC}_{50}$ in ITAs or RAs $(-7.53 \pm 0.58 \mathrm{vs}-7.19 \pm 0.07$ $\log \mathrm{M}$ in ITAs and $-7.93 \pm 0.88 \mathrm{vs}-7.68 \pm 0.29 \log \mathrm{M}$ in RAs, $P>.05)$.

\section{Discussion}

The major findings of this study are as follows: 1) The combination of a second-generation dihydropyridine and NO donor (NTG) can be used for relieving vasospasm in the arterial grafts (both ITA and RA) in CABG. 2) This cocktail may also prevent vasospasm related to a number of vasoconstrictors, including depolarizing mechanism, thromboxane $\mathrm{A}_{2}$, and $\alpha$-adrenoceptor-mediated vasospasm. 3) The cocktail maximally protects endothelial function in the arterial grafts.

\section{Vasospasm Problems in Arterial Grafting}

From both theoretic and practical aspects, arterial grafting is better than venous grafting. In fact, the patency rates of saphenous vein grafts in the early reports were unsatisfactory. The occlusion rate of saphenous vein grafts in the first year
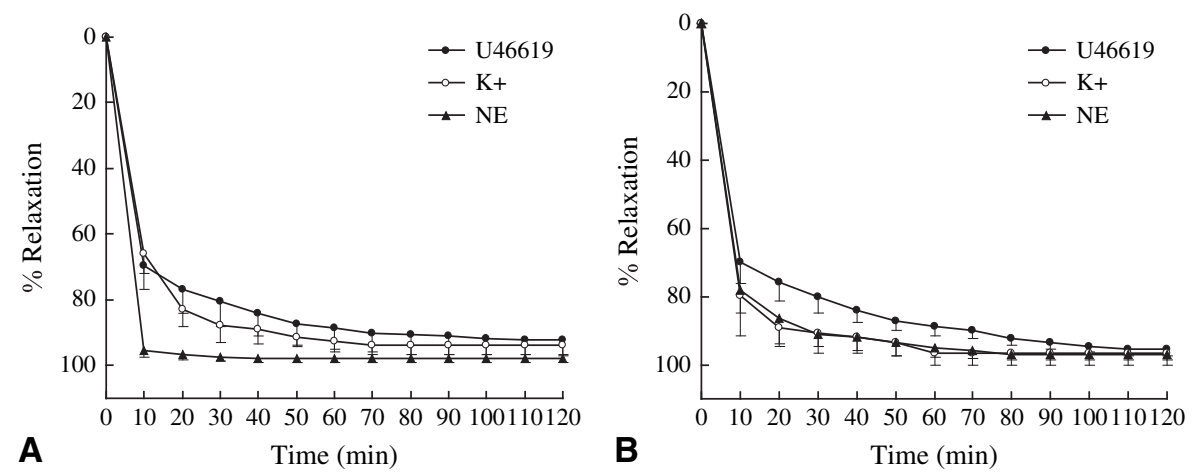

Figure 2. Onset and time course of the relaxation induced by nicardipine (30 $\mu \mathrm{mol} / \mathrm{L}$ ) and glycerol trinitrate (nitroglycerin, NTG, $30 \mu \mathrm{mol} / \mathrm{L}$ ) in ITA $(A, n=8)$ and $R A(B, n=6)$ rings precontracted by $\mathrm{U}_{46619}(10 \mathrm{nM}), \mathrm{K}^{+}$(70 $\mathrm{mmol} / \mathrm{L})$, or NE (10 $\mu \mathrm{M})$. Values are expressed as mean \pm SE. Note that in the first 20 minutes, relaxation reached almost the maximal in both ITA and RA rings. $N E$, Norepinephrine; $K^{+}$, potassium chloride. 

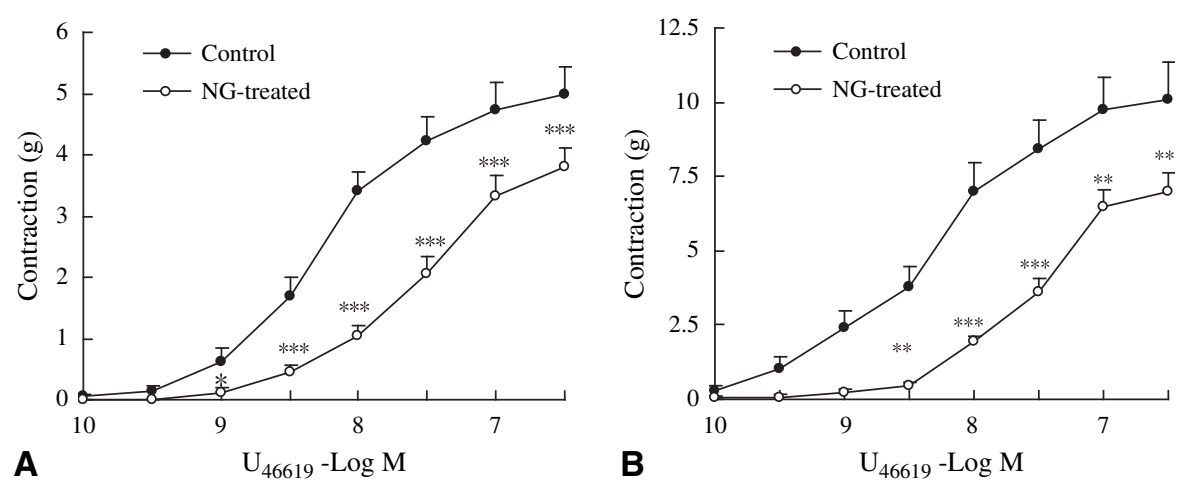

Figure 3. Mean concentration-contraction $(\mathrm{g})$ curves for $\mathrm{U}_{46619}(-10$ to -6.5 $\log M)$ in ITA $(A, n=8)$ and $R A(B, n=$ 7) rings pretreated with or without (control) treatment of NG (nicardipine 30 $\mu \mathrm{mol} / \mathrm{L} ; \mathrm{NTG} 30 \mu \mathrm{mol} / \mathrm{L}$ ) for 30 minutes. Values are expressed as mean $\pm \mathrm{SE}$. ${ }^{* *} \boldsymbol{P}<.01,{ }^{* * *} \boldsymbol{P}<.001$, compared with control. NG, Nicardipine and nitroglycerin.

is $10 \%$ to $26 \% .^{32-34}$ By 10 years, $50 \%$ of the grafts are occluded $^{35,36}$ and of the grafts still patent, $50 \%$ show marked atherosclerotic changes. ${ }^{34}$ Although compared with 30 years ago, the patency of saphenous vein grafts has improved to $78 \%$ at 5 years, $60 \%$ at 10 years, and $50 \%$ at 15 years because of advances in venous grafting techniques, ${ }^{37}$ it is still not comparable to arterial grafting. As a result, arterial grafting has been popular since the 1980s, and ITAs and RAs are most frequently used now. ${ }^{4,36,37}$ On the other hand, because of the tendency of vasospasm development in arterial grafts that may cause mortality or morbidity, antispastic protocols became essential for arterial grafting. For ITAs, the use of vasodilator drugs is a routine practice. $6,7,9,10,12,13,18,19,25,26$ For RAs, it was the use of calcium antagonists that made the revival of this graft after the initial abandonment, ${ }^{4}$ and a number of antispastic protocols have been recommended for RA grafting ever since. ${ }^{11,16,17,20,21-24,27}$ However, as to the best antispastic protocol, there is no unanimous opinion because of the variable availability of vasodilator drugs at different locations and the surgeon's preference. Further, the pharmaceutical development may also become a factor in the evolution of the antispastic protocol.

\section{Cause of Vasospasm: Various Vasoconstrictors}

We have systemically investigated the effect of various vasodilator drugs on arterial grafts regarding both the vasodilatory effect in established vasoconstriction and the prophylactic effect on vasoconstriction. These studies indicated that there is no single vasodilator drug that is effective against all vasoconstrictors. $^{1,28,30,37-42}$ This is because the real cause of vasospasm - the extreme form of vasoconstriction - is unknown, although it may be related to a number of causes.

In general, vasospasm could be the response of a vessel to many stimulants. ${ }^{40}$ These stimulants may be physical (eg, mechanical stimulation or temperature changes) or pharmacologic (eg, nerve stimulation or vasoconstrictor substances). Exogenous and endogenous vasoconstrictors are particularly important for vasoconstriction and its extreme form, vasospasm.

There are many vasoconstrictor substances that are related to vasospasm, as we outlined previously. ${ }^{40}$ In addition, arginine vasopressin is also a spasmogen for grafts. ${ }^{42}$ When vasospasm occurs, it is often unknown which of the above vasoconstrictors is involved and to what degree. The interaction among the vasoconstrictors may also play a role in the mechanism of vasospasm.

In view of the complexity of the mechanism of vasospasm mentioned above, it is difficult to choose the "best" method to solve (relief or prevent) vasospasm. However, it is most likely that vasodilator substance(s) that are effective against all the above mechanisms would be the most reliable clinical method. $\alpha$-adrenoceptor antagonists (eg, phentolamine and phenoxybenzamine) are only effective against $\alpha$-adrenoceptor agonists but ineffective to any other receptor-mediated

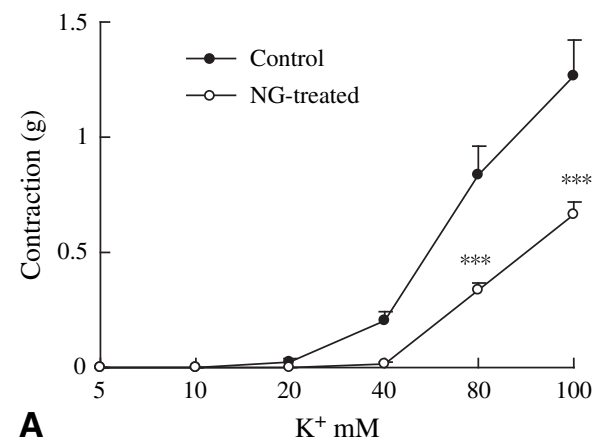

A $\mathrm{K}^{+} \mathrm{mM}$

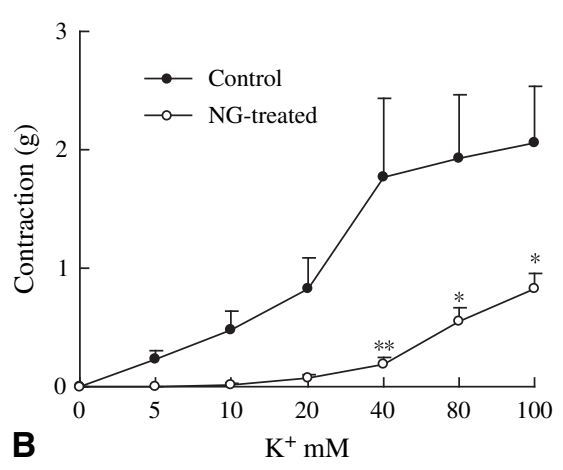

Figure 4. Mean concentration-contraction $(\mathrm{g})$ curves for $\mathrm{K}^{+}(5-100 \mathrm{mmol} / \mathrm{L})$ in $\operatorname{ITA}(A, n=8)$ and $R A(B, n=7)$ rings pretreated with or without (control) treatment of NG (nicardipine $30 \mu \mathrm{mol} /$ L; NTG $30 \mu \mathrm{mol} / \mathrm{L}$ ) for 30 minutes. Values are expressed as mean $\pm S E$. ${ }^{* *} P<.01$, ${ }^{* * * P}<.001$, compared with control. NG, Nicardipine and nitroglycerin. 

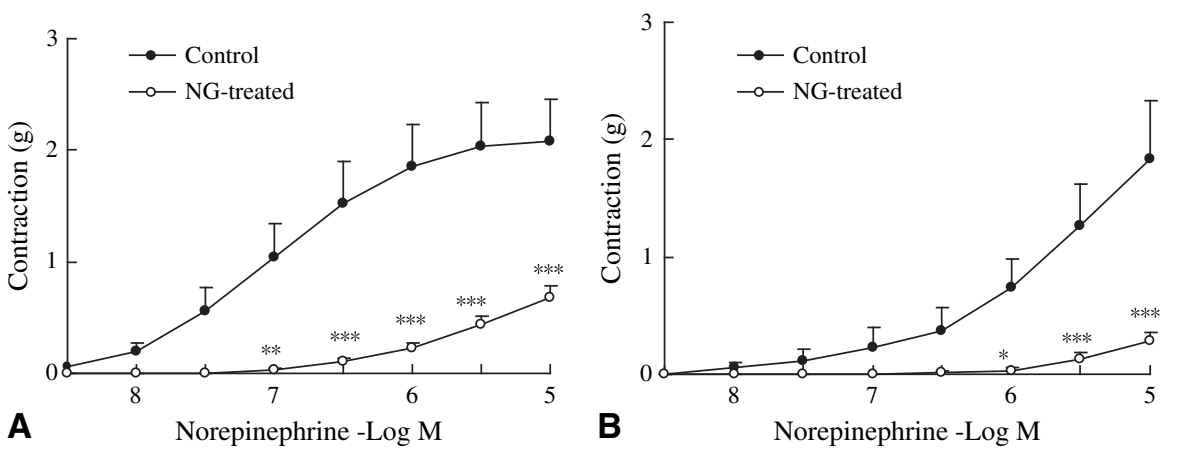

Figure 5. Mean concentration- (mmol/L) contraction $(\mathrm{g})$ curves for $\mathrm{NE}(-8.5$ to -5 $\log M)$ in (A) ITA $(n=8)$ and (B) RA $(n=$ 7) rings pretreated with or without (control) treatment of NG (nicardipine 30 $\mu \mathrm{mol} / \mathrm{L} ; \mathrm{NTG} 30 \mu \mathrm{mol} / \mathrm{L}$ ) for 30 minutes. Values are expressed as mean $\pm \mathrm{SE}$. ${ }^{* *} P<.01,{ }^{* * *} P<.001$, compared with control. NG, Nicardipine and nitroglycerin. (eg, thromboxane $\mathrm{A}_{2}$ ) or membrane depolarization-mediated $\left(\mathrm{eg}, \mathrm{K}^{+}\right)$contraction. Similarly, calcium antagonists are particularly effective in reversing or preventing membrane potential depolarizing agent potassium ion-mediated contraction. This is because calcium antagonists particularly inhibit voltage-dependent calcium channels, but they are relatively ineffective in $\alpha$-adrenoceptor ${ }^{38}$ or other receptors, such as thromboxane $\mathrm{A}_{2}$-mediated contraction. With regard to the clinically useful NO donor NTG and nitroprusside, they are particularly effective in reversing the contraction mediated by a number of receptor-mediated vasoconstrictors, such as $\alpha$-adrenoceptor, ${ }^{1,43}$ thromboxane A2, ${ }^{1}$ angiotensin-II, ${ }^{44}$ and the $\mathrm{K}^{+}$-mediated contraction. Further, we have demonstrated that vasodilators that are effective in relaxing contracted vessels may not be as effective in preventing vasoconstriction. This is particularly true for the NO donor NTG. ${ }^{1}$ In contrast, calcium antagonists (including nicardipine) are particularly effective in preventing $\mathrm{K}^{+}$-mediated contraction in both the ITA $^{1}$ and RA. ${ }^{31}$ These observations led us to believe that a combination of vasodilator drugs would be the best choice to prevent or relieve vasospasm. ${ }^{3,8,11,29} \mathrm{We}$ previously developed a cocktail composed of verapamil and NTG that has been demonstrated to be effective against all the above mechanisms. We demonstrated that among the 3 most important calcium antagonists, dihydropyridine nifedipine was the most potent. However, during that time (1980s), there were no intravenous dihydropyridine preparations available; therefore, verapamil was chosen for the cocktail because it was the next potent calcium antagonist. Verapamil had a good relaxation effect, better than diltiazem, and it was available as an intravenous preparation. The topical and intraluminal uses of VG solution have been proved effective in arterial grafting, ${ }^{3,8,11}$ and even intracoronary artery injection through catheterization was reported by us ${ }^{17}$ and others. ${ }^{45,46}$ However, verapamil has a bradycardia effect, particularly when beta-blockers are used, and therefore simultaneous systemic use of verapamil and beta-blockers is usually contraindicated. Instead, nicardipine, as the second generation of dihydropyridine calcium antagonist, is used frequently during CABG for intravenous dripping as an antispastic protocol for arterial grafting. ${ }^{22}$ We previously demonstrated that nicardipine has a satisfactory relaxation effect on arterial grafts such as ITA and RA against depolarizing mechanisms. ${ }^{31,47}$ We therefore designed the present study to develop a new cocktail for an antispastic protocol.

The present study investigated the effect of this cocktail solution on the 2 major arterial grafts: ITA and RA. We therefore have good reason to believe that this cocktail would provide excellent antispastic effect in clinical use for arterial grafting. The solution is designed mainly for topical spray or intraluminal injection into arterial grafts because it is made of intravenous injection preparations, as we previously used for VG solution. In fact, the VG solution was used by others in catheterization for either coronary artery ${ }^{45}$ or neuroendovascular surgery. ${ }^{46}$ We anticipate that this new NG cocktail can also be used for these purposes. Figure E2 illustrates the antispastic mechanism of the NG cocktail that is effective against known vasoconstrictors.

\section{Integrity of Function of Endothelium and Smooth Muscle}

The key role of endothelium in maintaining vascular tone and preventing atherosclerosis has been well documented. Our results have clearly shown that the NG solution has no adverse effect on endothelium; in other words, the endothelium of ITAs and RAs is well preserved by the NG solution, demonstrated by normal endothelium-dependent relaxation to $\mathrm{ACh}$ after treatment with $\mathrm{NG}$ for more than 30 minutes (Figure E1).

Further, dihydropyridine derivatives have been demonstrated to relax blood vessels through endotheliumdependent mechanisms by increasing endothelial nitric oxide synthase expression in the endothelial cell, in addition to its calcium antagonism mechanism in the smooth muscle. ${ }^{48}$ Therefore, the use of dihydropyridine derivatives may provide an additional benefit in the protection of endothelium-smooth muscle function in the grafts.

A common idea in antispastic protocols in CABG is to make the grafts fully relaxed with the expectation of no contraction at all. The ideal is that this may make the graft 
a "well-dilated" conduit to maximally carry blood flow to the coronary system. A typical example of this kind of antispastic protocol is using phenoxybenzamine, ${ }^{21}$ which is a "permanent" inhibitor of $\alpha$-adrenoceptor, meaning that once phenoxybenzamine is used, the $\alpha$-adrenoceptor of the vessel is permanently deactivated. However, there are 2 concerns about this concept. First, as expected, the specific $\alpha$-adrenoceptor inhibitor phenoxybenzamine has little or no effect against all other vasoconstrictors, as mentioned before. Second, we believe that in CABG, a graft should have its integrity regarding its receptors allocated in both endothelium and smooth muscle. A well-functioning graft should be able to relax and contract; it is the balance between contraction and relaxation that maintains the graft as a "living conduit." The normal contraction and relaxation of a vessel is a basic physiologic requirement to maintain its function. For example, when the saphenous vein graft is prepared by distention under high pressure, the structure of the wall of the vein is destroyed and the vein becomes a "dead conduit," which is the major reason for the low patency of the venous graft. We therefore designed our antispastic protocols to maximally maintain the integrity of the vessel, both the endothelium and smooth muscle. The new NG cocktail fulfills this requirement because it maximally protects the endothelium and the receptors of the smooth muscle.

\section{Conclusions}

The use of second-generation dihydropyridine, nicardipine and NO donor NTG cocktail, provides a new antispastic protocol that has a rapid onset, full relaxation, and an excellent prophylactic effect against all known mechanisms of vasospasm and maximally protects the endothelial and smooth muscle function of the ITA and RA. The cocktail is therefore expected to provide a new method in treating grafts during CABG with the best antispastic effect and protection of the graft.

The technical assistance of the cardiac surgeons and nurses in the cardiovascular operating room (Kay Metsger, Victor Bayley, Wendy Buckham, Verna Hilburger, Donna DiModica, and Kate Donaldson) at St Vincent Hospital is gratefully acknowledged.

\section{References}

1. He GW, Buxton B, Rosenfeldt F, Angus JA. Reactivity of human isolated internal mammary artery to constrictor and dilator agents. Implications for treatment of internal mammary artery spasm. Circulation. 1989;80(Suppl). I-141-50.

2. Sarabu MR, McClung JA, Fass A, Reed GE. Early postoperative spasm in left internal mammary artery bypass grafts. Ann Thorac Surg. 1987; 44:199-200.

3. He GW, Buxton BF, Rosenfeldt FL, Angus JA, Tatoulis J. Pharmacologic dilatation of the internal mammary artery during coronary bypass grafting. J Thorac Cardiovasc Surg. 1994;107:1440-4.

4. Acar C, Jebara VA, Portoghese M, Beyssen B, Pagny JY, Grare P, et al. Revival of the radial artery for coronary bypass grafting. Ann Thorac Surg. 1992;54:652-60.
5. He GW. Arterial grafts for coronary surgery: vasospasm and patency rate. J Thorac Cardiovasc Surg. 2001;121:431-3.

6. Mills NL. Preparation of the internal mammary artery graft with intraluminal papaverine. J Card Surg. 1991;6:318-21.

7. Frierson JH, Bigelow JC, Duke DJ, Mahoney TM, Dimas AP. Treatment of perioperative mammary artery graft spasm with nifedipine. Am Heart J. 1993;125:884-6.

8. He GW, Rosenfeldt FL, Angus JA. Pharmacological relaxation of the saphenous vein during harvesting for coronary artery bypass grafting. Ann Thorac Surg. 1993;55:1210-7.

9. Koike R, Kimura H. Dilating effects of isosorbide dinitrate on diameter of internal thoracic artery graft. J Thorac Cardiovasc Surg. 1993;105: $1121-2$.

10. Izzat MB, West RR, Ragoonanan C, Angelini GD. Effect of systemic vasodilators on internal mammary artery flow. Implications for postoperative treatment after myocardial revascularization. $J$ Thorac Cardiovasc Surg. 1994;108:82-5.

11. He GW, Yang CQ. Use of verapamil and nitroglycerin solution in preparation of radial artery for coronary grafting. Ann Thorac Surg. 1996;61: 610-4.

12. Uydes-Dogan BS, Nebigil M, Aslamaci S, Onuk E, Kanzik I, Akar F. The comparison of vascular reactivities of arterial and venous grafts to vasodilators: management of graft spasm. Int J Cardiol. 1996;53: $137-45$.

13. Akar F, Uydes-Dogan BS, Tufan H, Aslamaci S, Koksoy C, Kanzik I. The comparison of the responsiveness of human isolated internal mammary and gastroepiploic arteries to levcromakalim: an alternative approach to the management of graft spasm. Br J Clin Pharmacol. 1997;44:49-56.

14. Ali AT, Montgomery WD, Santamore WP, Spence PA. Preventing gastroepiploic artery spasm: papaverine vs calcium channel blockade. J Surg Res. 1997;71:41-8.

15. Chavanon O, Cracowski JL, Hacini R, Stanke F, Durand M, Noirclerc M, et al. Effect of topical vasodilators on gastroepiploic artery graft. Ann Thorac Surg. 1999;67:1295-8.

16. Garcia-Rinaldi R, Soltero ER, Carballido J, Mojica J. Intraluminal milrinone for dilation of the radial artery graft. Tex Heart Inst J. 1999; 26:189-91.

17. He GW, Fan KY, Chiu SW, Chow WH. Injection of vasodilators into arterial grafts through cardiac catheter to relieve spasm. Ann Thorac Surg. 2000;69:625-8.

18. Sogo N, Campanella C, Webb DJ, Megson IL. S-nitrosothiols cause prolonged, nitric oxide-mediated relaxation in human saphenous vein and internal mammary artery: therapeutic potential in bypass surgery. Br J Pharmacol. 2000;131:1236-44.

19. Yorgancioglu C, Tokmakoglu H, Gunaydin S, Catav Z, Suzer K. An alternative application of sodium nitroprusside to overcome perioperative spasm of the internal thoracic artery. Cardiovasc Surg. 2001;9:64-7.

20. Chanda J, Brichkov I, Canver CC. Prevention of radial artery graft vasospasm after coronary bypass. Ann Thorac Surg. 2000;70:2070-4.

21. Taggart DP, Dipp M, Mussa S, Nye PC. Phenoxybenzamine prevents spasm in radial artery conduits for coronary artery bypass grafting. J Thorac Cardiovasc Surg. 2000;120:815-7.

22. Radermecker MA, Grenade T, Cao-Thian SK, Defraigne JO, Lavigne JP, Van Damme H, et al. Nicardipine protocol for CABG using the radial artery clinical and angiographic data. Acta Chir Belg. 2001; 101:185-9.

23. Harrison WE, Mellor AJ, Clark J, Singer DR. Vasodilator pre-treatment of human radial arteries; comparison of effects of phenoxybenzamine vs papaverine on norepinephrine-induced contraction in vitro. Eur Heart J. 2001;22:2209-16.

24. Conant AR, Shackcloth MJ, Oo AY, Chester MR, Simpson AW, Dihmis WC. Phenoxybenzamine treatment is insufficient to prevent spasm in the radial artery: the effect of other vasodilators. $J$ Thorac Cardiovasc Surg. 2003;126:448-54.

25. Koramaz I, Ozkan M, Kesim M, Güven KY, Kadioglu M, Ulku C, et al. The contracting and relaxing responses of human internal mammary artery grafts harvested by two different methods. Pharmacol Res. 2005;51:567-73. 
26. Qi XR, Yan Y, Ma XD, Li TY, Nie XY, Yang BB. Development of a local vasodilator delivery system using fibrin glue to prevent arterial graft from spasm. J Biomed Mater Res A. 2007;82:139-44.

27. Ozdemir C, Ikizler M, Besogul Y, Karakaya A, Sirmagul B. An alternative agent for radial arterial graft spasm: application of topical iloprost. Scand Cardiovasc J. 2007;41:201-6.

28. He GW, Angus JA, Rosenfeldt FL. Reactivity of the canine isolated internal mammary artery, saphenous vein, and coronary artery to constrictor and dilator substances: Relevance to coronary bypass graft surgery. J Cardiovasc Pharmacol. 1988;12:12-22.

29. He GW. Verapamil plus nitroglycerin solution maximally preserves endothelial function of the radial artery: comparison with papaverine solution. J Thorac Cardiovasc Surg. 1998;115:1321-7.

30. He GW, Shaw J, Hughes CF, Yang CQ, Thomson DS, McCaughan B, et al. Predominant alpha 1-adrenoceptor mediated contraction in the human internal mammary artery. J Cardiovasc Pharmacol. 1993;21: 256-63.

31. He GW, Yang CQ. Comparative study on calcium channel antagonists in the human radial artery: clinical implications. $J$ Thorac Cardiovasc Surg. 2000;119:94-100.

32. FitzGibbon GM, Leach AJ, Keon WJ, Burton JR, Kafka HP. Coronary bypass graft fate. Angiographic study of 1,179 vein grafts early, one year, and five years after operation. J Thorac Cardiovasc Surg. 1986; 91:773-8.

33. Bourassa MG, Campeau L, Lesperance J, Grondin CM. Changes in grafts and coronary arteries after saphenous vein aortocoronary bypass surgery: results at repeat angiography. Circulation. 1982;65(7 Pt 2): 90-7.

34. Grondin CM, Campeau L, Lesperance J, Enjalbert M, Bourassa MG. Comparison of late changes in internal mammary artery and saphenous vein grafts in two consecutive series of patients 10 years after operation. Circulation. 1984;70:I208-12.

35. Okies JE, Page US, Bigelow JC, Krause AH, Salomon NW. The left internal mammary artery: the graft of choice. Circulation. 1984;70: I213-21.

36. Lytle BW, Loop FD, Cosgrove DM, Ratliff NB, Easley K, Taylor PC. Long-term (5 to 12 years) serial studies of internal mammary artery and saphenous vein coronary bypass grafts. $J$ Thorac Cardiovasc Surg. 1985;89:248-58.

37. Shah PJ, Gordon I, Fuller J, Seevanayagam S, Rosalion A, Tatoulis J, et al. Factors affecting saphenous vein graft patency: clinical and angiographic study in 1402 symptomatic patients operated on between 1977 and 1999. J Thorac Cardiovasc Surg. 2003;126:1972-7.

38. He GW, Acuff TE, Ryan WH, Yang CQ, Douthit MB, Bowman RT, et al. Inhibitory effects of calcium antagonists on $\alpha$-adrenoceptormediated contraction in the human internal mammary artery. Br J Clin Pharmacol. 1994;37:173-9.

39. He G-W, Yang C-Q, Mack MJ, Acuff TE, Ryan WH, Starr A. Interaction between endothelin and vasodilators in the human internal mammary artery. Br J Clin Pharmacol. 1994;38:505-12.

40. He G-W, Yang C-Q, Starr A. An overview of the nature of vasoconstriction in arterial grafts for coronary surgery. Ann Thorac Surg. 1995;59:676-83.

41. He GW. Arterial grafts for coronary artery bypass grafting: biological characteristics, functional classification, and clinical choice. Ann Thorac Surg. 1999;67:277-84.

42. Wei W, Floten HS, He GW. Interaction between vasodilators and vasopressin in internal mammary artery and clinical significance. Ann Thorac Surg. 2002;73:516-22.

43. He GW, Shaw J, Yang CQ, Hughes C, Thomson D, McCaughan B, et al. Inhibitory effects of glyceryl trinitrate on alpha-adrenoceptor mediated contraction in the human internal mammary artery. Br J Clin Pharmacol. 1992;34:236-43.

44. He GW, Yang CQ. Comparison of nitroprusside and nitroglycerin in inhibition of angiotensin II and other vasoconstrictor-mediated contraction in human coronary bypass conduits. Br J Clin Pharmacol. 1997;44: 361-7.

45. Chen CW, Lin CL, Lin TK, Lin CD. A simple and effective regimen for prevention of radial artery spasm during coronary catheterization. Cardiology. 2006;105:43-7. Epub 2005 Oct 27.

46. Eskioglu E, Burry MV, Mericle RA. Transradial approach for neuroendovascular surgery of intracranial vascular lesions. J Neurosurg. 2004; 101:767-9.

47. He GW. Radial artery grafting: clinical antispastic protocols. In: $\mathrm{He} \mathrm{GW}$, ed. Arterial Grafting for Coronary Artery Bypass Surgery. Chapter 17. 2nd Edition. New York, NY: Springer-Verlag Berlin Heidelberg; 2006: $156-62$.

48. Kobayashi N, Mori Y, Mita S, Nakano S, Kobayashi T, Tsubokou Y, et al. Effects of cilnidipine on nitric oxide and endothelin-1 expression and extracellular signal-regulated kinase in hypertensive rats. Eur J Pharmacol. 2001;422:149-57. 


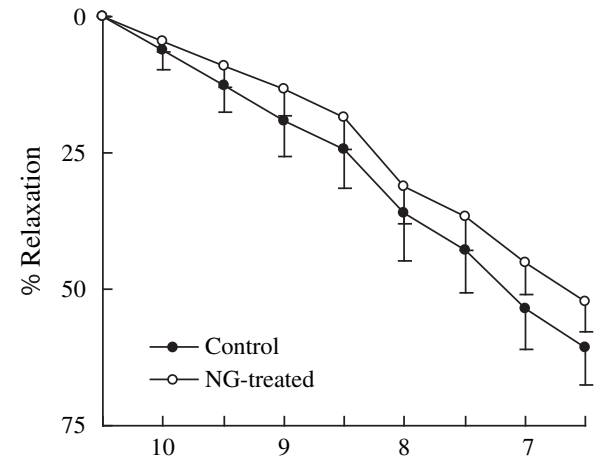

A

Acetylcholine -Log M

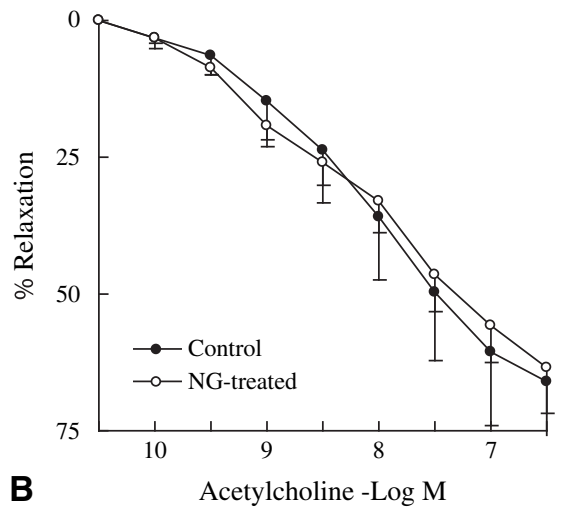

Figure E1. Mean concentration- $(\log M)$ relaxation (\%) curves for $\mathrm{ACh}(-10$ to $-6.5 \log M)$ in $U_{46619}$-contracted ITA $(A, n=6)$ and $R A(B, n=8)$ rings pretreated with or without NG (nicardipine $30 \mu \mathrm{mol} / \mathrm{L} ; \mathrm{NTG} 30 \mu \mathrm{mol} / \mathrm{L}$ ) for $30 \mathrm{~min}$ utes. Values are expressed as mean \pm SE. $P>.05$, compared with control (2-way analysis of variance followed by Bonferroni tests). NG, Nicardipine and nitroglycerin. 
Schema of Antispastic Effect of NG Cocktail

\section{Components of NG Cocktail Vasospasm Mechanism}

NTG

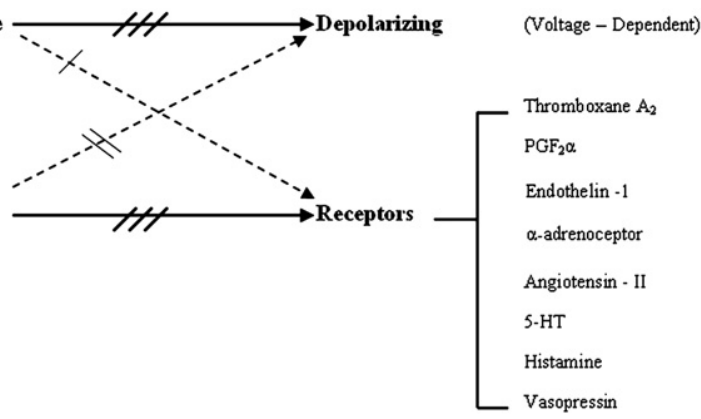

Figure E2. Schema showing the mechanism of the antispastic effect of NG cocktail. Nicardipine, as a calcium channel blocker, is particularly effective against the mechanism of vasoconstriction through membrane depolarization that is voltage-dependent ${ }^{31}$ but less effective in receptor-mediated mechanisms. In contrast, NTG, as an NO donor, is effective in all mechanisms and particularly effective in receptor-mediated mechanisms. ${ }^{1}$ NG, Nicardipine and nitroglycerin; NTG, nitroglycerin; $\boldsymbol{P G F}_{2 \alpha}$, prostaglandin F2 $\alpha$; 5-HT, 5-hydroxytryptamine. 